\title{
Modeling The Effect of Particle Size on Magnetic Nanoparticles using Modified Ising Model
}

\author{
Christian Fredy Naa \\ Department of Electrical Engineering (Mechatronics), \\ Faculty of Industrial Technology, Parahyangan Catholic University \\ Jalan Ciumbeuleuit No. 94, Bandung, Indonesia \\ christian.fredy@unpar.ac.id
}

\begin{abstract}
In this article, the Ising model has been modified to simulate the effect of particle size on magnetic nanoparticles properties especially hole-doped manganites. The objective of this research is to give an insight and clear understanding about magnetic nanoparticles especially the effect of the particle size. The model considers common accepted magnetic nanoparticles theoretical model where each particle consists of core and surface/boundary part. The model mimics the particles size as a clusters or group of spins. The modification of Ising Model lies on the the spins that designated as either core or boundary particles and differs for their exchange energy. The model predicts magnetization, coercivity, hysteresis and magnetic characteristics of core and boundary of the nanoparticles. Here, we simulate $3 \times 3$ up to $7 \times 7$ cluster size and it was found that magnetization increases as the cluster size increases. The results are in a good agreement qualitatively with experimental results. The results can be explained by the domination of the boundary spin properties to the core counterpart on the smaller cluster size. The model also gives insight to the micro-states of the spin at each clusters for zero-field-cooled experiment.
\end{abstract}

Keywords: boundary, clusters, core, Ising model, microstates, nanoparticles

\begin{abstract}
Abstrak
Artikel ini membahas model Ising yang dimodifikasi untuk memodelkan pengaruh ukuran partikel terhadap sifat nanopartikel magnetik terutama manganites. Tujuan dari riset ini adalah untuk memberikan pengertian yang lebih dalam tentang nanopartikel magnetik terutama pengaruh ukuran butiran. Model ini menggunakan model teoritik nanopartikel dimana setiap partikel terdiri dari bagian inti dan permukaan. Model yang dibangun menganalogikan ukuran partikel sebagai gugus/kumpulan spin. Modifkasi dari model Ising terletak pada Spin yang ditetapkan didefinisikan sebagai bagian inti atau permukaan dan memiliki energi interaksi yang berbeda. Model yang dibangun dapat memprediksi karakteristik magnetisasi, coercivity, histerisis serta karakteristik magnetisasi dari bagian inti dan permukaan nanopartikel. Di sini disimulasikan ukuran kluster $3 \times 3$ hingga $7 \times 7$ dan nilai magnetisasi meningkat seiring ukuran kluster meningkat. Hasilnya cocok secara kualitatif dengan hasil eksperimen. Hasil ini dapat dijelaskan dengan dominasi sifat bagian permukaan terhadap bagian inti pada ukuran kluster yang lebih kecil. Model ini juga dapat memberikan gambaran tentang keadaan mikro spin pada gugus model untuk eksperimen zero-field-cooled.
\end{abstract}

Kata Kunci: gugus, inti, keadaan mikro, model Ising, nanopartikel, permukaan

\section{INTRODUCTION}

M AGNETIC nanoparticles are those materials in nanometer (nm) size (approximately 1-100 nm) that show a response to magnetic field. Magnetic nanoparticles are a great interest for applications in biomedicine [1] [2], magnetic energy storage [3], information storage and spintronics [4]. Magnetic 
nanoparticles show interesting properties comparing to their bulk-sized counterparts. The key reason is as the size of particle decreases, it causes the increase fraction of boundary atoms, which has different properties from those of the bulk/core atoms [5].

Among the magnetic nanoparticles, the hole-doped manganites compounds with perovskite structure are well-known for their magnetoresistance properties [6], [7], [8]. The role of the particle size in these magnetic nanoparticles has attracted much attention in both experimentation and theoretical perspective [9], [10], [11], [12], [13]. Experimentally, the particle size has given various effects in properties such as magnetization, coercivity, hysteresis behavior, Curie temperature and electrical transport.

Theoretically, the most accepted model is the core-shell structure of spin model [14]. This model considers the nanoparticles are divided into the core/bulk and shell/surface/boundary parts, where the core has stronger ferromagnetic ordering than the boundary whose thickness is estimated around 3 $\mathrm{nm}$ [15]. Using this model, the boundary contribution is larger for smaller particles and therefore the magnetization is diminished in a proportional way [15]. However, to verify the model we have to establish a computational modeling and show related properties that affected by the particle size.

In this article we pursue the question of modeling the effect of particle size in magnetic materials especially hole-doped manganites. We modify Ising Model to mimics the magnetic nanoparticles. The modification lies by differing exchange energy between core and boundary part of the nanoparticles, we are able to obtain key results that agree qualitatively with experimental results.

\section{LITERATURE REVIEW}

The research of particle size effect on magnetic nanoparticles especially in hole-doped manganites begins by several researchers when investigated the magnetoresistance properties in $\mathrm{La}_{0.7} \mathrm{Sr}_{0.3} \mathrm{MnO}_{3}$ polycrystalline [16], [17], [18]. It was found that the magnetoresistance of polycrystalline is larger over a wide temperature compare to single-crystal [19], [20] and epitaxial film [21]. In particular, Gupta et al. [21] have directly compared the properties of polycrystalline and epitaxial films of $\mathrm{La}_{0.67} \mathrm{Sr}_{0.23} \mathrm{MnO}_{3}$, $\mathrm{La}_{0.67} \mathrm{Ca}_{0.23} \mathrm{MnO}_{3}$ and $\mathrm{La}_{0.75} \mathrm{MnO}_{3}$ films. They explained the difference in magnetoresistance is because of switching of magnetic domains in the nanoparticles and spin disorder in nanoparticles boundary region.

The research continue by investigating the influence of particle size to various properties such as magnetization, coercivity, Curie temperature and hysteresis behavior [13], [22], [23], [24]. The researchers altered the particle size by modify the annealing temperature of the synthesis process. It was found that the magnetization, coercivity and Curie temperature increases as the particle size increases. Hwang et al. [23] emphasis the particle size effect is caused by the properties of bulk and and interface of the nanoparticles. Gaur and Varma [22] suspect that the phenomena were caused by the extra formation of particles boundaries as the annealing temperature decreases, leading to enhanced broken bonds at the boundary which cause decreases in magnetization value. Zhang et al. [24] suspects the boundaries between neighboring particles act as potential barrier. Rivas et al [13] also pointed the boundary contribution to the variety of properties. These findings clearly emphasis on the structure of the nanoparticles that consist by core and boundary particles.

Low temperature behavior of magnetic nanoparticles manganites has been investigated by several researchers [25], [26], [27], [28], [29]. To investigate this behavior, two kinds of measurement namely zero-field cooled (ZFC) and field-cooled (FC) usually performed. In ZFC measurement, the magnetization were measured as the temperature raises from low temperature to high temperature (heating process). Meanwhile in FC measurement, the magnetization were measured when sample were cooled from high temperature to low temperature (cooling process). For both measurement, researchers have found that in term of magnetization value, the process are not reversible.

López-Quintela et al. [15] proposed a model for magnetic nanoparticles in which the inner part would have the same magnetic and transport properties as the inner (bulk) compound, but the outer (boundary) layer would contain defects that lead to magnetically disordered state (zero magnetization). The model schematically shown in Figure 1. The width of the boundary part is approximately $3 \mathrm{~nm}$. The existence of the core and boundary of the nanoparticles is supported by the high resolution transmission electron microscopy [14] for nanoparticle of $\mathrm{La}_{0.67} \mathrm{Ca}_{0.33} \mathrm{MnO}_{3}$ and $\mathrm{La}_{0.7} \mathrm{Sr}_{0.3} \mathrm{MnO}_{3}$. Moreover, Zhang et al. [14] 
claimed that the exchange energy at the boundary can minimize the interface exchange energy. Since it proposed, the core-boundary model has been well accepted to give explanation the effect of particle size to the properties of magnetic nanoparticles. However, to the best of our knowledge there is no computation modeling to show the consequence of this core-shell model. The computation modeling is necessary to give insight and further understanding about the effect of the particle size of magnetic nanoparticles.

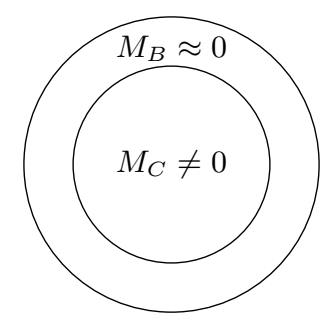

Figure 1: Proposed model for manganite nanoparticles. $M_{C}$ and $M_{B}$ are the magnetizations of the core and boundary of the particles, respectively, schematic reproduced from [15].

\section{RESEARCH METHOD}

\section{A. Ising Model}

The Ising model assumes that the magnetic material consists of discrete variables of dipole moments or spins. These spins are assumed as scalar variable $s_{k}$, which only take two values: +1 or -1 ; representing spin up or down dipoles of unit magnitude. The interaction between nearest neighbors governs by exchange energy denotes by $J$. The spins also can be influenced by external magnetic field $H$. Thus, the simplest Hamiltonian of the Ising model takes the form:

$$
\mathcal{H}=-\sum_{<k l>} J_{k l} s_{k} s_{l}-H \sum_{k} s_{k},
$$

where notation $\langle k l\rangle$ indicates that the sites $k$ and $l$ as nearest neighbours. The exchange energy $J_{k l}$ governs the strength of the interaction between sites $k$ and $l$. For a ferromagnetic model, the exchange energy of $J_{k l}$ takes positive value, in this case the spins are tend to line up with one another. As opposed, if the exchange energy of $J_{k l}$ takes negative value, the spins are tend to anti-parallel with one another (anti-ferromagnetic). The spins also prone to line up as the same direction of external magnetic field $H$.

The Hamiltonian function gives the total energy of the system in particular state. Thus, the system has discrete sets of states with its own energy, from lowest or ground state energy $E_{0}$ to much higher energy $E_{1}, E_{2}, E_{3}, \ldots$. The dynamics of the Ising model occurs when the system interact with its surrounding namely the thermal energy and external magnetic field.

The probability of finding the system in given configuration $i$ is given by

$$
P_{i}=\frac{1}{Z} e^{-E_{i} / K_{B} T},
$$

here, $E_{i}$ denotes the energy of the state $i, K_{B}$ denotes the Boltzmann constant and $T$ denotes temperature. It is conventional to use symbol $\beta$ to denote the quantity $1 / K_{B} T, Z$ is a normalizing constant also known as partition function whose value is given by

$$
Z=\sum_{i} e^{-\beta E_{i}}
$$

where the sum extends over all micro-states. The probability $P_{i}$ is used in order to calculate the expectation value such as mean energy $\langle E\rangle$ or total magnetization $\langle M\rangle$ at a given temperature $T$. The total energy for a specific configuration $i$ is given by 


$$
E_{i}=-J \sum_{\langle k l\rangle} s_{k} s_{l}
$$

The total magnetization at the state $i$ is defined as

$$
M_{i}=\sum_{j=k}^{N} s_{k},
$$

where $N$ denotes the total number of spins and the sum is taken for all spins at a given configuration $i$. The average energy and magnetization of the Ising system per spin are obtained by dividing Eq. 4 and Eq. 5 by the total number of spins $N$.

In this work, the Ising model is solved by an algorithm developed by Metropolis et al. [30]. Metropolis et al. modified the Monte Carlo method to evaluate the change in configuration of the spins. The new spins configuration are generated from the previous one using transition probability that depends on the difference of energy between those states. The sampling function in for finding the system in a state $s$ is given by

$$
P_{s}=\frac{e^{-\beta E_{s}}}{Z}
$$

with energy $E_{s}$ and $Z$ is a normalization constant defines the partition function, as given by

$$
Z(\beta)=\sum_{s} e^{-\beta E_{s}}
$$

To compute the partition function, all states must be calculated. Fortunately, the Metropolis algorithm considers only ratio between probabilities of the states, in such the partition function do not need to be calculated. The algorithm goes as follows:

1) Establish an initial state with energy $E_{b}$ by generating random configuration in the lattice.

2) Change the configuration by flipping one spin randomly. Compute the energy of this trial configuration $E_{t}$.

3) Calculate the difference of those energies $\Delta E=E_{t}-E_{b}$. In two-dimensional case, the values of $\Delta E$ is limited to five possible values.

4) If $\Delta E \leq 0$ accept the new configuration. In this case, the energy is lowered and hopefully the system is moving towards the minimum energy at given temperature.Update the expectation values: energy and magnetization

5) If $\Delta E>0$, calculate $w=e^{-\Delta E / K_{B} T}$.

6) Compare $w$ with a random number $r$, if $r \leq w$, accept the new configuration, else keep the old configuration

7) Update the expectation values: energy and magnetization.

8) Repeat steps (2)-(7) in order to obtain sufficiently good representation of the states.

One Monte Carlo cycle is defined each time the algorithm sweeps through all spins. One can think that one of such cycle is a measurement. Finally, the expectation values divided by the number of cycles and the number of spins to obtain the average expectation values per spin.

\section{B. Modified Ising Model for Magnetic Nanoparticles}

We use the modifed Ising model to study the influence of particle size of magnetic nanoparticle size. We use the well accepted core-boundary model, proposed by López-Quintela et al. [15] (Figure 1) We considers the assumptions of our model:

1) In this model, the regular two-dimension Ising model structure is used where the distances between sites are equal.

2) The nanoparticles is divided into two parts, the core of and the boundary of the nanoparticles.

3) One site in Ising model represents either core or boundary particle.

4) The particle size is modeled using clusters. 
5) This model uses periodic boundary condition.

6) The interaction of sites between cores, between boundaries and between boundary-core are different in terms of exchange energy $J$ between them.

7) The standard calculations of Ising Model by using Metropolis algorithm were taken to calculate magnetization of the spin as a function of temperature and magnetic field.

The schematic of the model is shown in Figure 2. The governing equation for this model is the standard Hamiltonian as explained in Eq. 1, but with modified exchange energy:

$$
\begin{gathered}
\mathcal{H}=-J \sum_{\langle k l\rangle} s_{k} s_{l}-H \sum_{k} s_{k}, \text { where } \\
J= \begin{cases}J_{1} & \text { if } k \& l \text { are core and boundary } \\
J_{2} & \text { if } k \& l \text { are boundaries } \\
J_{3} & \text { if } k \& l \text { are cores. }\end{cases}
\end{gathered}
$$

By using this simple model, some properties are able to be observed. For simplicity, dimensionless parameters were taken to observe those properties.

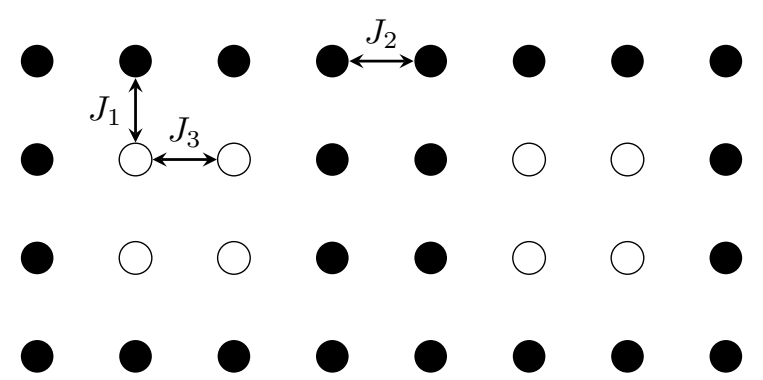

Figure 2: Model of magnetic nanoparticles of modified Ising Model, in this case $4 \times 4$ clusters size. Black circles are boundaries and white circles are cores of the nanoparticles. Here, $J_{1}$ denotes the exchange energy between core and boundary, $J_{2}$ denotes the exchange energy between boundaries and $J_{3}$ denotes the exchange energy between cores of the nanoparticles.

\section{RESUlTS AND Discussion}

\section{A. Magnetization as a function of temperature and magnetic field}

The parameters that were used in our simulations are $J_{1}=0.5, J_{2}=1, J_{3}=3, K_{B}=1, H=0.05$. The measurements were occurred for $T=0.1$ until $T=12,10^{5}$ Monte Carlo cycles are taken to average all the observable parameters. The simulations were field-cooled (FC): it were taken from during cooling from high temperature to low temperature. Cluster size $3 \times 3$ to $7 \times 7$ were simulated. All properties were calculated in mean value by dividing by number of sites. The model were simulated by using processor Intel Core i5 3.2 GHz with 8GB RAM. It took about 5-6 hours to finish all the Monte Carlo cycles.

Mean magnetization $\langle M\rangle$ as a function of temperature $T$ is shown in Figure 3. The mean magnetization values decreases as the cluster size decreases, similar to references found in [13], [22], [23], [24] and [27]. All simulations for corresponding cluster size show the paramagnetic-ferromagnetic transition at a particular Curie temperature $\left(T_{C}\right)$. A slight variation of $T_{C}$ was observed for all cluster sizes. The transition temperature $T_{C}$ of the simulations were determined from the maxima of the $d M / d T$ versus $T$ curve. Figure 4 shows the variation of $T_{C}$ as a function of cluster size. As shown on the figure, the transition temperature increases as the cluster size increases.

We can explain the result as follow: as the size of the cluster decreases, the contribution of the boundary nanoparticles increases. The cluster $3 \times 3$ has 9 boundary sites compare to only 1 core site, comparing 


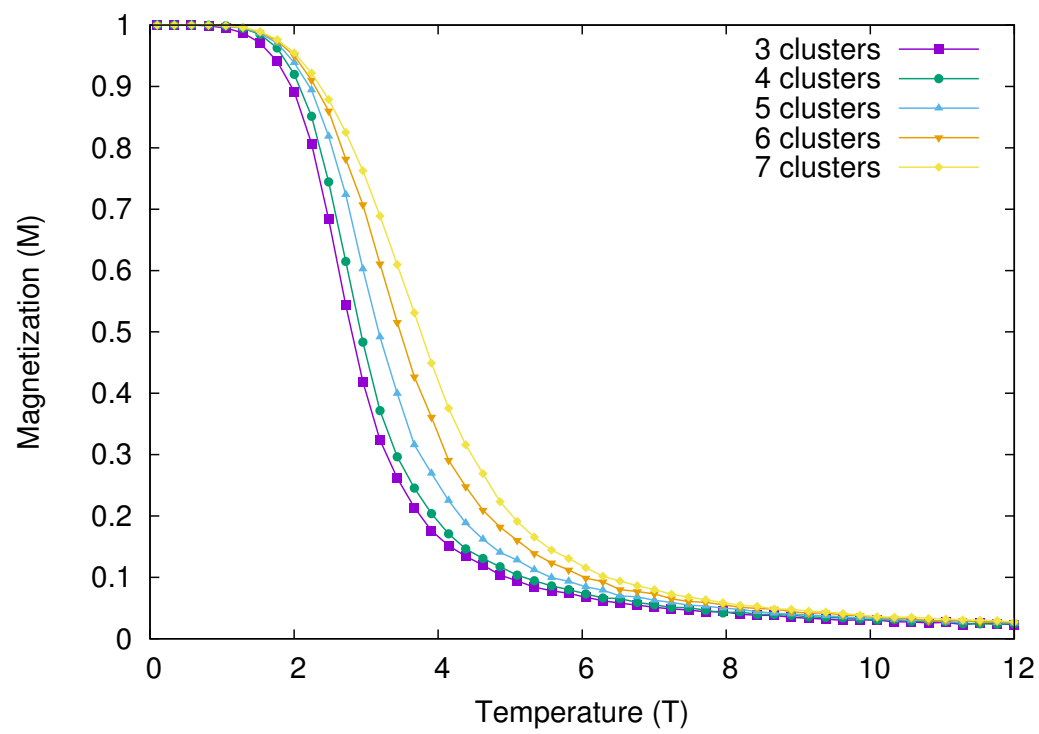

Figure 3: Temperature dependence of mean magnetization for $J_{1}=0.5, J_{2}=1, J_{3}=2$ and $H=0.05$

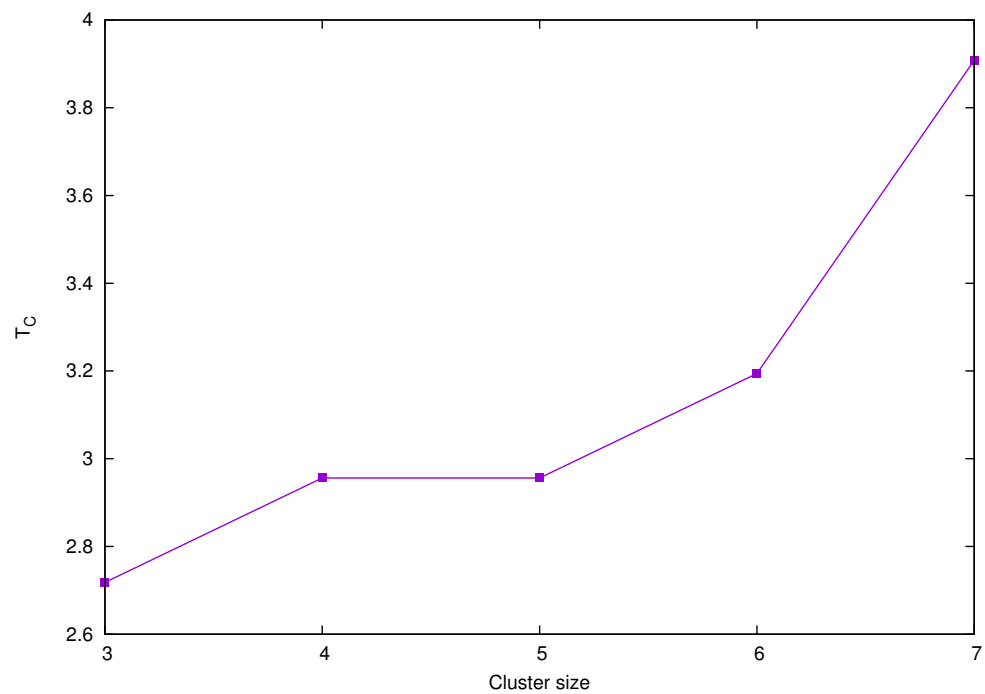

Figure 4: Transition temperature $T_{C}$ as a function of cluster size

to $7 \times 7$ that has 30 sites of boundary and 25 core. Thus, for $3 \times 3$ cluster size, the boundary effect dominate the core counterpart resulting in decreases in magnetization.

The mean magnetization as a function of external magnetic field from $H=-2$ to $H=2$ is shown in Figure 5 for $T=2$ and $T=8.5$. As shown, magnetization decreases on decreasing cluster size, this result is similar to references found in [22] dan [26]. This also indicates that ferromagnetic order is weakened on reducing cluster size [22].

Cluster size dependence of magnetic coercivity $H_{C}$ for $T=2$ is shown in Figure 6. The coercivity increases as cluster size increases, in agreement qualitatively with research conducted by Muthuselvam et al. [26]. We attribute the decreases in magnetization for smaller cluster is due to the domination of boundary particles. Compare $3 \times 3$ cluster which has 1 core and 8 boundaries with $7 \times 7$ which has 25 cores and 30 boundaries. Thus, the particle boundary play an important role in reducing the magnetization. 


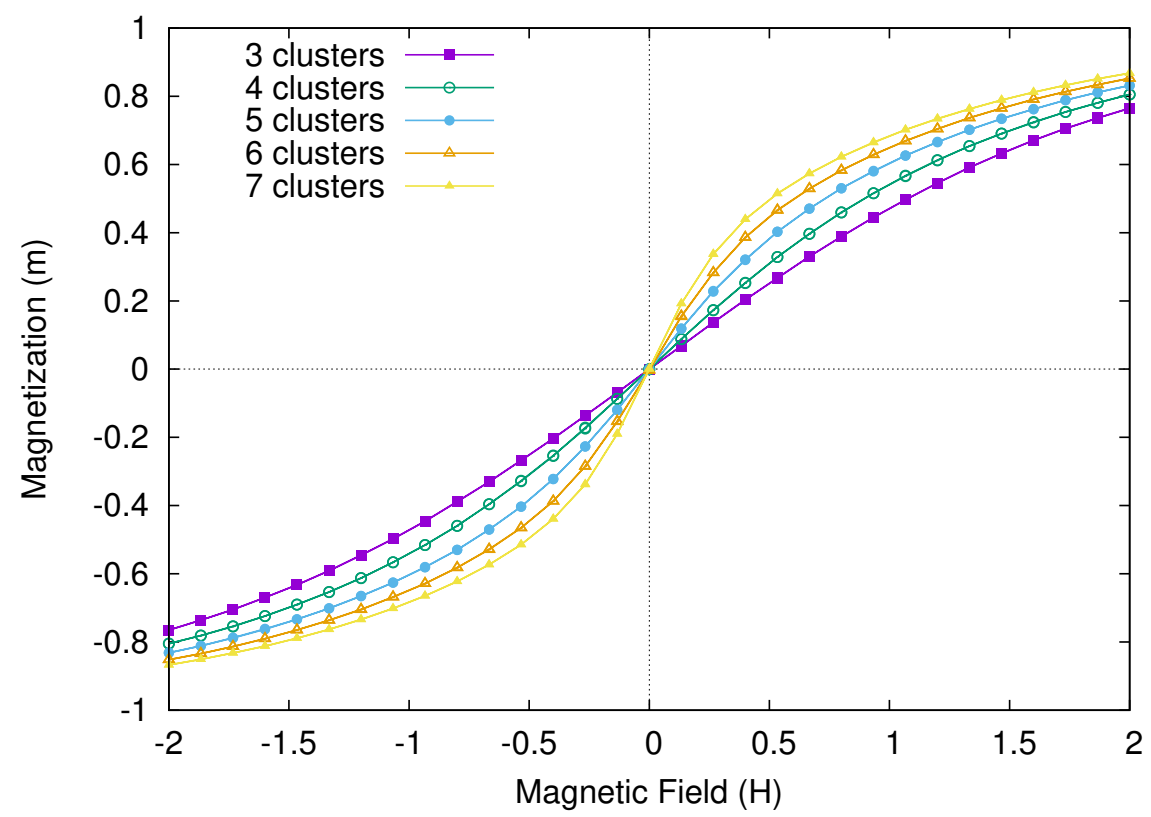

Figure 5: External magnetic field $H$ dependence of magnetization for parameters $J_{1}=0.5, J_{2}=0.1, J_{3}=3$ at temperature $T=8.5$.

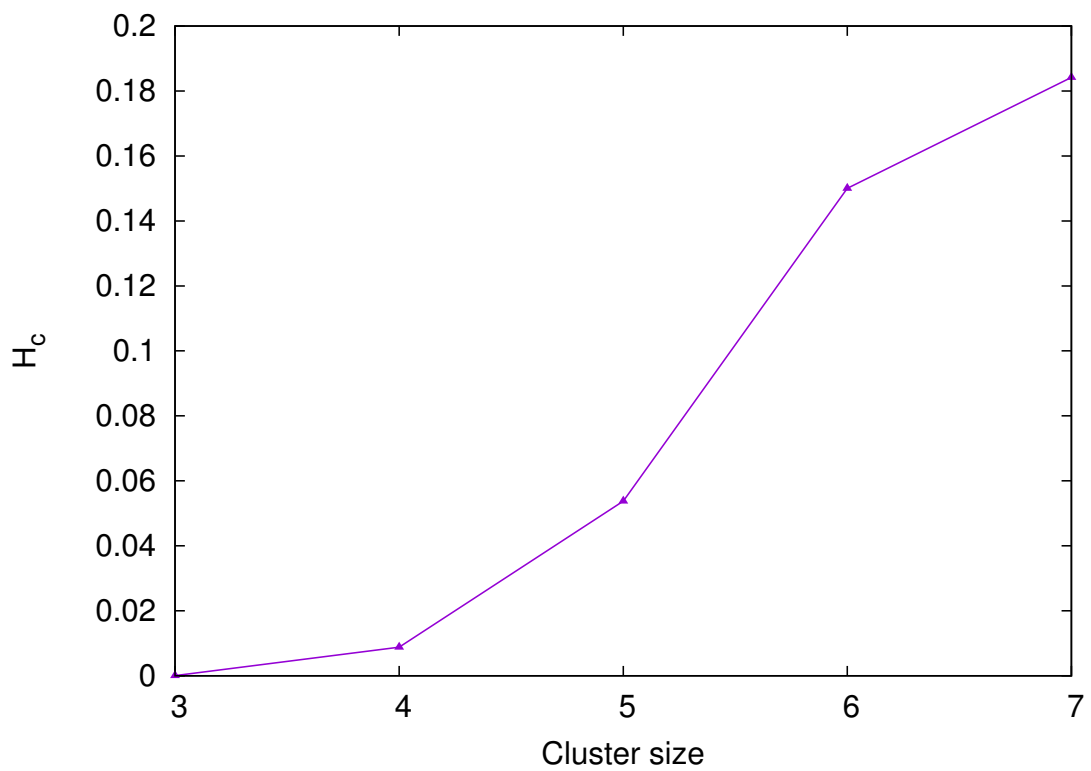

Figure 6: $H_{C}$ graph for $J_{1}=0.5, J_{2}=0.1, J_{3}=3$ at temperature $T=2$ as a function of cluster size

\section{B. Magnetic Properties of Core and Surface}

By using this model, it is possible to study the behavior of core and boundary. Figure 7 shows the magnetization as a function of temperature for core, boundary and overall magnetization for cluster size $7 \times 7$. As shown in the figure, the boundary part decay much faster than core part. This result confirms findings from Park et al. [31], they measured surface-boundary magnetization of $\mathrm{La}_{0.7} \mathrm{Sr}_{0.3} \mathrm{MnO}_{3}$ by using spin-resolved photoemission spectroscopy.

In their article Park et al. [31] were not sure due to experiment uncertainty, whether the boundary mag- 
netization $M_{B}$ near $T_{C}$ shows power law or linear-like the temperature dependence. By this simulation, it was confirmed that the boundary magnetization $M_{B}$ shows power law according to equation

$$
M(T)=A T^{\gamma}
$$

It also found that the $\gamma$ decreases as the cluster size increases, cluster size dependence to $\gamma$ is shown in Figure 8. The same analysis was also performed for core part and overall magnetization. Moreover, it also found that the $\gamma$ decreases as the cluster size increases.

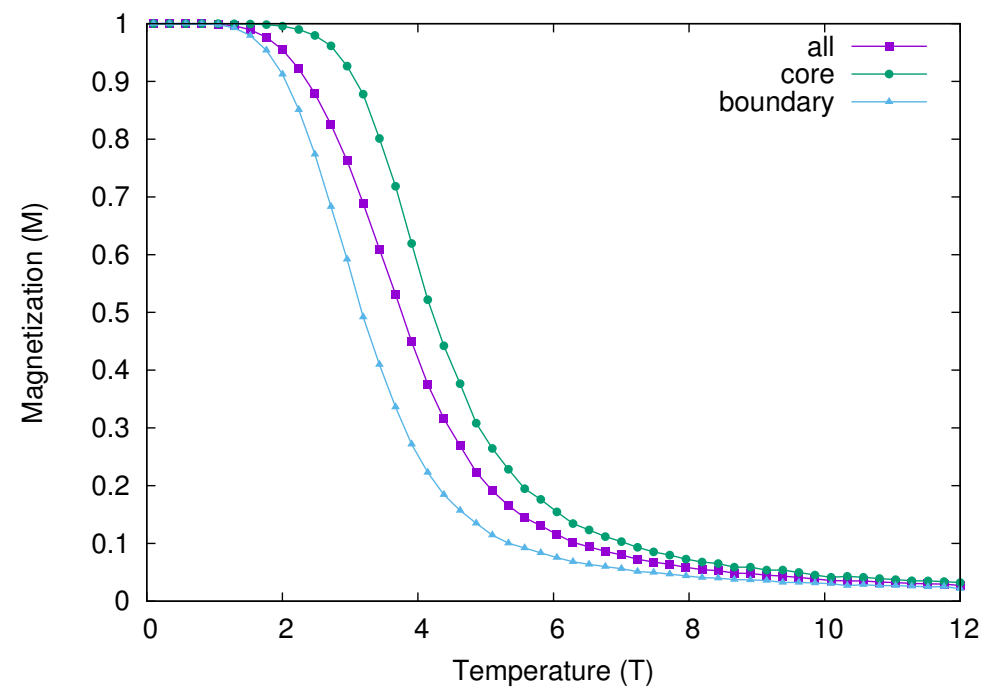

Figure 7: Temperature dependence of magnetization for core, boundary and overall for cluster size $7 \times 7$. Parameters are $J_{1}=0.5, J_{2}=0.1, J_{3}=2, H=0.05$

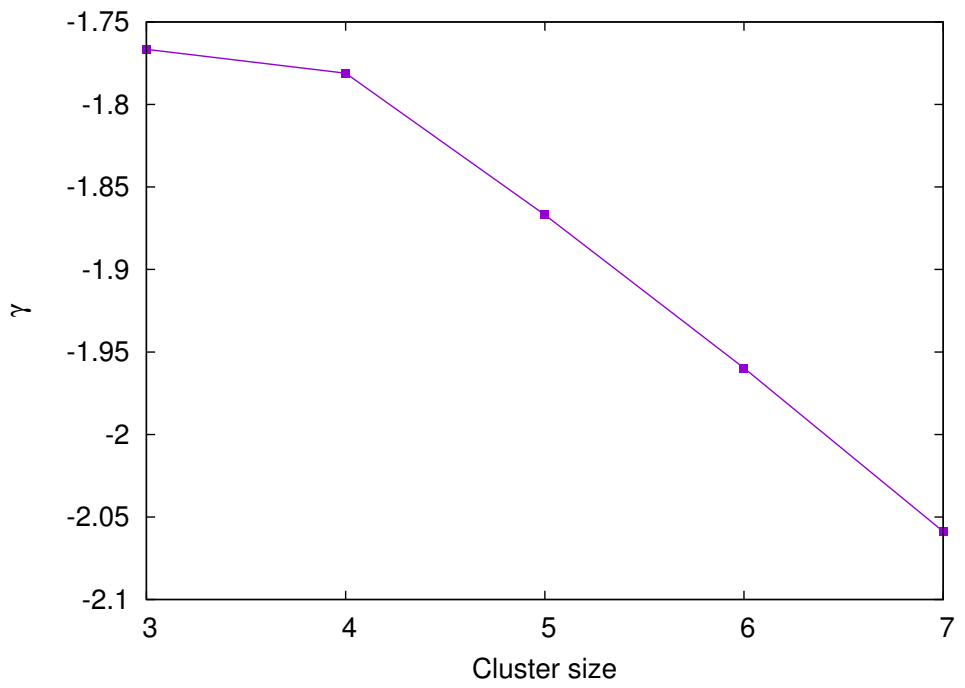

Figure 8: Cluster size dependence of $\gamma$ value for boundary magnetization part $J_{1}=0.5, J_{2}=0.1, J_{3}=2, H=0.05$

\section{Zero-Field Cooled and Field-Cooled Properties - insight on micro-states}

This section shows the simulation for $\mathrm{ZFC}$ and $\mathrm{FC}$ to study the low temperature behavior. Figure 9 shows ZFC and FC simulation for cluster size $3 \times 3,4 \times 4,5 \times 5$ and $7 \times 7$ for parameters $J_{1}=0.5, J_{2}=$ 
$1, J_{3}=2$ and under small magnetic field $H=0.05$. It can be seen that ZFC and FC are irreversible process, agree with experimental results found in references [25], [26], [27], [28] and [29]. At low temperature, ZFC magnetization is lower than the FC counterpart. The temperature when there occur separation between ZFC and FC magnetization is called irreversible temperature $T_{i r r}$. The temperature where the peak magnetization occurs in ZFC process is called blocking temperature $T_{B}$. As can be seen from the figures, in these simulations, $T_{i r r}$ is equal to $T_{B}$ for all cluster sizes, this equality are in good agreement qualitatively with result from Dyakonov et al. [29].
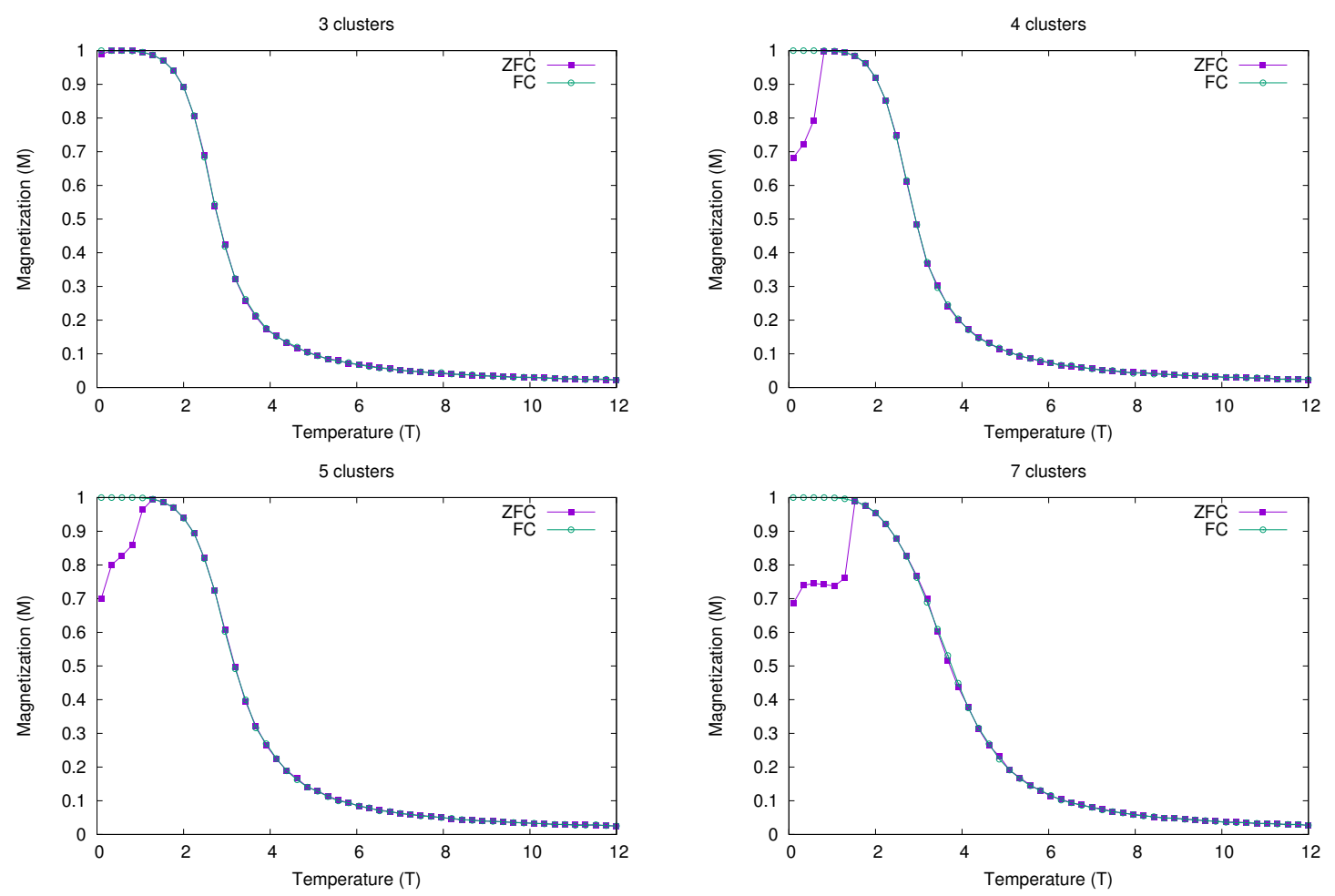

Figure 9: Temperature dependence of $\mathrm{ZFC}$ and FC magnetization for various cluster sizes

In these simulations, it has been found that $T_{i r r}$ and $T_{B}$ increases as the cluster size increases similar to the finding from Roy et al. [27]. It also can be found that with the increasing external magnetic field, the separation at low temperature for magnetization of ZFC and FC process become lower, consistent with the findings from Zhu et al. [28].

What actually happen during low temperature on ZFC and FC process is somehow puzzling. Muthuselvam and Bhowmik [26] states that magnetic irreversibility shows some intrinsic spin disorder and frustration related to the domain freezing in the ferromagnetic ground state. Zhu et al. [28] denotes the moments in the surface layer can freeze below $T_{i r r}$ and align with the direction of the moments in the core under FC process. Roy et al. [27] states that during this low temperature region, when the field is applied, only a component of the magnetization vector is observed along the field direction.

The findings in these simulations agrees with Roy et al. [27], in addition the simulations shows that these magnetization vectors are somehow unique to each cluster member. Figure 10 shows the ZFC and FC curves for cluster size $4 \times 4$ and $7 \times 7$ and the corresponding micro-states snapshots during low temperature and much higher one. As seen from the microstates at low temperature for ZFC process, the magnetization vector that align with external magnetic field are somehow uniquely localized inside the cluster. In fact, this phenomena occurs for all size of cluster. This finding could contribute to the science of ZFC process and can be proved in the future experimentally. 

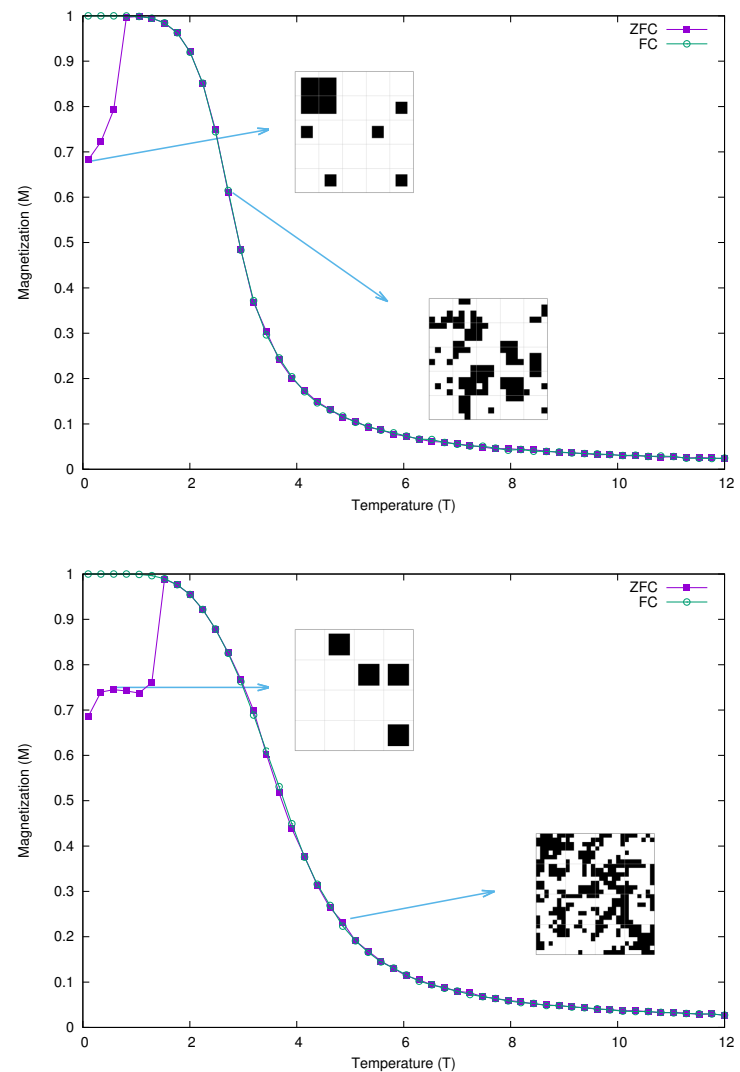

Figure 10: ZFC - FC curves and corresponding micro-states for cluster size $4 \times 4$ (top) and $7 \times 7$ (bottom)

\section{CONCLUSION}

In conclusions, we have presented the modified Ising model to study the effect of particle size on magnetic nano particles. We underlie the model based on core-boundary theoretical model. The modification of the original Ising model lies on the kind of the spin that designated either as core or boundary part of the nanoparticles. The modified model considers those two kinds differ in their exchange energy. The model has shown key results namely magnetization as a function of temperature and magnetic field, coercivity, Curie temperature and low temperature behavior by using ZFC and FC simulation. All the results agree qualitatively with experimental results performed by other researchers. We simulated $3 \times 3$ up to $7 \times 7$ cluster size and it was found that magnetization increases as the cluster size increases. By these results, we are able to confirm that core and boundary part of the magnetic nanoparticles has different value in exchange interaction resulting in the domination of boundary part to the core counterpart on the smaller cluster size. We also able to give insight of the micro states for the low temperature phenomena in $\mathrm{ZFC}$ and FC measurement where the magnetization vector are somehow uniquely localized inside the cluster.

\section{REFERENCES}

[1] Reju Thomas, In-Kyu Park, and Yong Jeong. Magnetic iron oxide nanoparticles for multimodal imaging and therapy of cancer. International journal of molecular sciences, 14(8):15910-15930, 2013.

[2] QA Pankhurst, NTK Thanh, SK Jones, and J Dobson. Progress in applications of magnetic nanoparticles in biomedicine. Journal of Physics D: Applied Physics, 42(22):224001, 2009.

[3] Natalie A Frey, Sheng Peng, Kai Cheng, and Shouheng Sun. Magnetic nanoparticles: synthesis, functionalization, and applications in bioimaging and magnetic energy storage. Chemical Society Reviews, 38(9):2532-2542, 2009. 
[4] Srikanth Singamaneni, Valery N Bliznyuk, Christian Binek, and Evgeny Y Tsymbal. Magnetic nanoparticles: recent advances in synthesis, self-assembly and applications. Journal of Materials Chemistry, 21(42):16819-16845, 2011.

[5] Sergey P Gubin. Magnetic Nanoparticles: Preparation and Properties. Encyclopedia of Surface and Colloid Science, Third Edition, 74(6):3934-3948, 2015.

[6] Z.X. Cheng, H.F. Zhen, A.H. Li, X.L. Wang, and H. Kimura. CMR $\mathrm{La}_{0.7} \mathrm{Ca}_{0.3} \mathrm{MnO}_{3}$ and $\mathrm{La}_{0.7} \mathrm{Sr}_{0.3} \mathrm{MnO}_{3}$ thin films fabricated by sol-gel method. Journal of Crystal Growth, 275(1-2):2415-2419, 2005.

[7] M. Khlifi, M. Bejar, O. EL Sadek, E. Dhahri, M.A. Ahmed, and E.K. Hlil. Structural, magnetic and magnetocaloric properties of the lanthanum deficient in $\mathrm{La}_{0.8} \mathrm{Ca}_{0.2} \mathrm{MnO}_{3}$ manganites oxides. Journal of Alloys and Compounds, 509(27):7410 - 7415, 2011.

[8] M Zarbali, A Göktaş, IH Mutlu, S Kazan, AG Şale, and F Mikailzade. Structure and magnetic properties of $\mathrm{La}_{0.66} \mathrm{Sr}_{0.33} \mathrm{MnO}_{3}$ thin films derived using sol-gel technique. Journal of superconductivity and novel magnetism, 25(8):2767-2770, 2012.

[9] H. Baaziz, A. Tozri, E. Dhahri, and E. K. Hlil. Effect of particle size reduction on the structural, magnetic properties and the spin excitations in ferromagnetic insulator $\mathrm{La}_{0.9} \mathrm{Sr}_{0.1} \mathrm{MnO}_{3}$ nanoparticles. Ceramics International, 41(2):2955-2962, 2015.

[10] H. Baaziz, N. K. Maaloul, A. Tozri, H. Rahmouni, S. Mizouri, K. Khirouni, and E. Dhahri. Effect of sintering temperature and grain size on the electrical transport properties of $\mathrm{La}_{0.67} \mathrm{Sr}_{0.33} \mathrm{MnO}_{3}$ manganite. Chemical Physics Letters, 640:77-81, 2015.

[11] P. A. Yadav, A. V. Deshmukh, K. P. Adhi, B. B. Kale, N. Basavaih, and S. I. Patil. Role of grain size on the magnetic properties of $\mathrm{La}_{0.7} \mathrm{Sr}_{0.3} \mathrm{MnO}_{3}$. Journal of Magnetism and Magnetic Materials, 328:86-90, 2013.

[12] MH Ehsani, ME Ghazi, P Kameli, and J Moradi. Size dependence of electrical properties of $\mathrm{La}_{0.8} \mathrm{Sr}_{0.2} \mathrm{MnO}_{3}$ nanoparticles. Journal of Superconductivity and Novel Magnetism, 29(11):2969-2977, 2016.

[13] J Rivas, LE Hueso, A Fondado, F Rivadulla, and MA Lopez-Quintela. Low field magnetoresistance effects in fine particles of $\mathrm{La}_{0.67} \mathrm{Ca}_{0.33} \mathrm{MnO}_{3}$ perovskites. Journal of magnetism and magnetic materials, 221(1):57-62, 2000.

[14] T Zhang, X P Wang, Q F Fang, and X G Li. Magnetic and charge ordering in nanosized manganites. Citation: Applied Physics Reviews J. Appl. Phys, 1(82):31302-6181, 2014.

[15] M. A. López-Quintela, L. E. Hueso, J. Rivas, and F. Rivadulla. Intergranular magnetoresistance in nanomanganites. Nanotechnology, 14(2):212-219, 2003.

[16] P. Schiffer, A. P. Ramirez, W. Bao, and S-W. Cheong. Low temperature magnetoresistance and the magnetic phase diagram of $\mathrm{La}_{2 / 3} \mathrm{Ca}_{x} \mathrm{MnO}_{3}$. Phys. Rev. Lett., 75:3336-3339, Oct 1995.

[17] R Mahendiran, R Mahesh, AK Raychaudhuri, and CNR Rao. Composition dependence of giant magnetoresistance in $\mathrm{La}_{1-x} \mathrm{Ca}_{x} \mathrm{MnO}_{3}(0.1 \leq x \leq 0.9)$. Solid state communications, 94(7):515-518, 1995.

[18] H. L. Ju, J. Gopalakrishnan, J. L. Peng, Qi Li, G. C. Xiong, T. Venkatesan, and R. L. Greene. Dependence of giant magnetoresistance on oxygen stoichiometry and magnetization in polycrystalline $\mathrm{La}_{0.67} \mathrm{Ba}_{0.33} \mathrm{MnO}_{z}$. Phys. Rev. B, 51:61436146, Mar 1995.

[19] HL Ju, C Kwon, Qi Li, RL Greene, and T Venkatesan. Giant magnetoresistance in $\mathrm{La}_{1-} \mathrm{Sr}_{x} \mathrm{MnO}_{z}$ films near room temperature. Applied physics letters, 65(16):2108-2110, 1994

[20] MF Hundley, M Hawley, RH Heffner, QX Jia, JJ Neumeier, J Tesmer, JD Thompson, and XD Wu. Transport-magnetism correlations in the ferromagnetic oxide $\mathrm{La}_{0.7} \mathrm{Ca}_{0.3} \mathrm{MnO}_{3}$. Applied physics letters, 67(6):860-862, 1995.

[21] A Gupta, G Q Gong, Gang Xiao, P R Duncombe, P Lecoeur, P Trouilloud, Y Y Wang, V P Dravid, and J Z Sun. Grainboundary effects on the magnetoresistance properties of perovskite manganite films. Physical Review B, 54(22):R15629R15632, 1996.

[22] Anurag Gaur and G D Varma. Sintering temperature effect on electrical transport and magnetoresistance of nanophasic $\mathrm{La}_{0.7} \mathrm{Sr}_{0.3} \mathrm{MnO}_{3}$. Journal of Physics: Condensed Matter, 18(39):8837-8846, 2006.

[23] H Y Hwang, S-w Cheong, N P Ong, and B Batlogg. Spin-polarized intergrain tunneling in $\mathrm{La}_{2 / 3} \mathrm{Sr}_{1 / 3} \mathrm{MnO}_{3}$. Physical Review Letters, 77(10):2041-2044, 1996.

[24] Ning Zhang, Weiping Ding, Wei Zhong, Dingyu Xing, and Youwei Du. Tunnel-type giant magnetoresistance in the granular perovskite $\mathrm{La}_{0.85} \mathrm{Sr}_{0.15} \mathrm{MnO}_{3}$ ning. Physical Review B, 56(13):8138-8142, 1997.

[25] P. Dey, T. K. Nath, P. K. Manna, and S. M. Yusuf. Enhanced grain surface effect on magnetic properties of nanometric $\mathrm{La}_{0.7} \mathrm{Ca}_{0.3} \mathrm{MnO}_{3}$ manganite: Evidence of surface spin freezing of manganite nanoparticles. Journal of Applied Physics, 104(10), 2008

[26] I. Panneer Muthuselvam and R. N. Bhowmik. Grain size dependent magnetization, electrical resistivity and magnetoresistance in mechanically milled La0.67 $\mathrm{Sr}_{0.33} \mathrm{MnO}_{3}$. Journal of Alloys and Compounds, 511(1):22-30, 2012.

[27] Sujoy Roy, Igor Dubenko, Dossah D Edorh, and Naushad Ali. Size induced variations in structural and magnetic properties of double exchange $\mathrm{La}_{0.8} \mathrm{Sr}_{0.2} \mathrm{MnO}_{3-\delta}$ nano-ferromagnet. Journal of applied physics, 96(2):1202-1208, 2004.

[28] T Zhu, BG Shen, JR Sun, HW Zhao, and WS Zhan. Surface spin-glass behavior in $\mathrm{La}_{2 / 3} \mathrm{Sr}_{1 / 3} \mathrm{MnO}_{3}$ nanoparticles. Applied Physics Letters, 78(24), 2001.

[29] V Dyakonov, A Ślawska-Waniewska, N Nedelko, E Zubov, V Mikhaylov, K Piotrowski, A SzytuŁa, S Baran, W Bazela, $\mathrm{Z}$ Kravchenko, et al. Magnetic, resonance and transport properties of nanopowder of $\mathrm{La}_{0.7} \mathrm{Sr}_{0.3} \mathrm{MnO}_{3}$ manganites. Journal of Magnetism and Magnetic Materials, 322(20):3072-3079, 2010.

[30] Nicholas Metropolis, Arianna W Rosenbluth, Marshall N Rosenbluth, Augusta H Teller, and Edward Teller. Equation of state calculations by fast computing machines. The journal of chemical physics, 21(6):1087-1092, 1953.

[31] J Park, E Vescovo, H Kim, C Kwon, R Ramesh, and T Venkatesan. Magnetic properties at surface boundary of a half-metallic ferromagnet $\mathrm{La}_{0.7} \mathrm{Sr}_{0.3} \mathrm{MnO}_{3}$. Physical Review Letters, 81(9):1953-1956, 1998. 
